\title{
Sexting scripts in adolescent relationships: Is sexting becoming the norm?
}

\section{Katrien Symons}

Higher Institute for Family Studies, Odisee, Belgium

\section{Koen Ponnet}

Department of Communication Sciences (MIOS), University of Antwerp, Belgium; Department of Communication Sciences (IMEC-MICT), Ghent University, Belgium

\section{Michel Walrave}

Department of Communication Sciences (MIOS), University of Antwerp, Belgium

\section{Wannes Heirman}

Department of Communication Sciences (MIOS), University of Antwerp; Artesis Plantijn University College, Belgium

\begin{abstract}
This study offers empirical insight into adolescents' norms around sexting. Informed by sexual scripting theory, we investigated the extent to which young people perceive sexting as being a likely behavior in the context of a romantic relationship (the "sexting script"). A distinction is made between what adolescents find likely among sameaged peers (the general sexting script) versus what they find likely in their personal situation (the personal sexting script). Data were gathered through questionnaires from adolescents aged 13-18years $(N=357,45 \%$ male). The results show that sexting scripts are gendered and that adolescents perceive sexting as being more likely to occur among peers than in their personal situation. The personal sexting script is related to the general sexting script, sexual experiences, and the use of online pornography. The
\end{abstract}

\section{Corresponding author:}

Symons Katrien, Higher Institute for Family Sciences, Odisee, Huart Hamoirlaan I36, 1030 Brussels,

Belgium.

Email: Katrien.Symons@odisee.be 
results of the study are useful for the design of sexting education and sensitization messages toward youth.

\section{Keywords}

Adolescence, sexting, sexual behavior, sexual scripts

Sexting refers to sending, receiving, and forwarding sexually explicit texts and images via cell phones or the Internet (Döring, 2014; Klettke et al., 2014). Public concern and academic interest, however, have mainly been directed at the digital communication of images, rather than text messages (Cooper et al., 2016; Lim, 2013). Exact prevalence rates of sexting differ widely across studies due to differences in their definition and methodology, but studies do suggest that it is not a marginal phenomenon among youth (Barrense-Dias et al., 2017; Cooper et al., 2016). A systematic review of the research literature came to a mean prevalence rate among adolescents of $12 \%$ for sending sexually suggestive images (with a $95 \% \mathrm{CI}=[5.06,18.85]$ ) and $16 \%$ for receiving such images (with a 95\% CI=[11.71, 19.57]; Klettke et al., 2014). Belgium, our home country, has a prevalence rate of $15 \%$ among young people aged $15-18$ years for sending sexually suggestive images (Van Ouytsel et al., 2014). In the research literature, sexting has largely been framed as inherently risky and as a deviant behavior that requires prevention and intervention (Chalfen, 2009; Hasinoff, 2016; Kosenko et al., 2017). Such a conceptualization is also criticized, however, for being normatively biased and denying sexual citizenship among youth (Angelides, 2013; Lee and Crofts, 2015; Willard, 2010). It is increasingly accepted that sexting can be seen as a developmentally normal behavior between young people, also referred to as the "normalcy discourse" around sexting (Barrense-Dias et al., 2017; Döring, 2014).

Studies that look at the context, motivations, and experiences of young people who sext offer insights into how sexting can be understood as a developmentally normal behavior. The typology of sexting proposed by Wolak and Finkelhor (2011), based on an analysis of the legal aspects of sexting cases, is a useful point of departure. They differentiate between "aggravated sexting" and "experimental sexting." Aggravated sexting involves adults or elements of abusive behavior, such as the nonconsensual distribution of sexual images, sexual abuse, extortion, or threats, whereas experimental sexting does not involve adults or abusive elements, and will be further referred to as "consensual sexting," which we argue better covers the rich set of experiences that it may refer to. Victimization by aggravated sexting can have far-reaching consequences, and studies on the nonconsensual sharing of sexually explicit media suggest that this type of behavior can be understood in terms of sexual and/or intimate partner violence (Walker and Sleath, 2017). A recent study with adolescents and young adults aged 13-30years found that $13 \%$ had distributed a sexting message (messages, photos, or videos) of someone else without consent (Morelli et al., 2016). It is important to keep in mind, however, that consensual sexting is by far more common among young people than aggravated sexting (Bianchi et al., 2016, 2017); the underlying motivations for engaging in 
consensual sexting include expressing one's sexuality with peers or romantic partners (sexual purposes) and reinforcing one's body image by obtaining feedback on one's physical appearance (Bianchi et al., 2016). Qualitative research suggests that sexting most commonly occurs with a current or potential partner, whereby it serves as part of or a substitute for offline sexual interactions (Lenhart, 2009; Willard, 2010). Also, quantitative research has confirmed that sexting among young people is primarily located in the realm of "romance as part of an existing relationship" (Mitchell et al., 2012). Sexting is consistently found to be more common among older adolescents (Baumgartner et al., 2014; Cooper et al., 2016) and among adolescents who are sexually active (GordonMesser et al., 2013; Temple and Choi, 2014), which further indicates that sending and receiving sexually suggestive images is part of the wider range of sexual behaviors young people may engage in when they start experimenting with sexual behavior or become romantically involved. Hence, from a normalcy discourse, (consensual) sexting is seen as an activity that can support young people in their sexual development and thus in terms of sexual agency, sexual expression, and exploration of their sexuality.

While sexting is linked to adolescents' sexual development and relationship experiences, there is little understanding of how sexting becomes part of young people's sexual repertoire. In studying sexual behavior among adolescents, peers are typically identified as important socializing agents. For example, young people who perceive their peers to be more sexually active are more likely to be sexually experienced themselves (Van de Bongardt et al., 2014). The aim of this study is to gain more insight into how sexting becomes part of adolescents' sexual repertoire by studying the perceived behavioral norms about sexting among peers and the adolescents' personal norms regarding the behavior. Sexual scripting theory (Gagnon and Simon, 2005) is used as a framework because it offers good opportunities for understanding the gender-specificity of norms toward sexting as well as for incorporating the role of personal behavior and experiences. The results of the study can have implications in terms of developing prevention programs and sensitizing messages toward youth who may engage in sexting.

\section{Background}

\section{A sexual scripting framework}

In sexual scripting theory, as developed by Gagnon and Simon (2005), sexuality and sexual behavior are primarily understood as social processes. In such a framework, a person's sexual conduct is seen as "scripted," guided, or informed by blueprints for appropriate behavior in a given context. Sexual scripts can be defined as containing "an individual's generalized knowledge about the typical elements of a sexual interaction, including expectations about the behaviors of the partner and normative beliefs about the appropriateness of specific behavioral activities" (Krahé et al., 2007b: 687). A sexual scripting framework posits that scripting takes place on three dimensions. The first dimension is cultural scenarios such as representations in the media and shared cultural understandings. The second dimension, interpersonal scripting, includes daily interactions and negotiations with other people, including the sexual partner, in which sexuality and sexual behavior are discussed. The third dimension is intra-individual scripting, whereby the individual 
interprets the input and material from cultural scenarios and interpersonal experiences (Masters et al., 2013; Morrison et al., 2015). Sexual scripts are gender-specific, implying that the behavior expected from a man differs from what is expected from a woman (Sakaluk et al., 2014; Wiederman, 2005). This gender-specificity finds its roots in gender ideology or shared beliefs about femininity and masculinity that are dominant in society and inform sexual scripts (Tolman et al., 2015). Typical features of a traditional sexual script are that men are focused on sexual pleasure and will initiate sexual activity, while women are more relationship focused and control their sexuality (Masters et al., 2013; Wiederman, 2005). Gender-specific sexual scripts become discernable in adolescence, as boys are typically expected to be sexually demanding and act as predators, whereas girls are expected to act as sexual gatekeepers (Tolman et al., 2015).

Sexual scripting theory has been successfully applied as a framework for understanding engagement in a variety of offline sexual interactions that are considered problematic. As such, the internalization of traditional gender-specific sexual scripts is linked to sexual risk-taking (Bowleg et al., 2015; Holman and Sillars, 2012) and sexual aggression and victimization (Krahé et al., 2007b; Ryan, 2011). Technology-mediated sexual conduct such as sexting, however, has primarily been understood from an individualistic perspective, pointing to individual risk and protective factors. Some research does indicate the importance of peer dynamics in influencing a young person's intentions as well as actual engagement in sexting (Vanden Abeele et al., 2014; Walrave et al., 2015). Sexting, measured broadly in terms of sending, asking for and receiving sexts, is also related to the young person's media consumption, including watching music videos and online pornography (Van Ouytsel et al., 2014). It is not well understood, however, what expectations young people have toward sexting (what sexting scripts they hold), the extent to which these sexting scripts are gender-specific, or what factors shape these scripts. This study contributes to such understanding by specifically focusing on adolescents' scripts for sexting in the context of a relationship.

\section{Gender-specificity of the sexting script}

Since culturally shared beliefs about femininity and masculinity inform sexual scripts (Tolman et al., 2015), it is plausible that such beliefs also inform sexting scripts, leading to different expectations for boys and girls. Regarding the prevalence rates of sending sexually suggestive images in adolescence, two review studies found inconsistent results across different studies, with some suggesting no gender difference and others suggesting that boys are more likely to send a picture than girls or vice versa (Cooper et al., 2016; Klettke et al., 2014).

The gender dynamics in sexting are clearly pronounced when it comes to the meanings attached to the behavior, as articulated in gender-specific motivations for engaging in the behavior, as well as gender-specific roles in the sexting-negotiation process and gender-specific consequences when engagement is made public. A North American qualitative study with young people (Davidson, 2014) showed that boys and girls are assigned different roles in the sexting-negotiation process. Concretely, boys are being perceived as the initiators and the ones who ask for sexual photos, while girls are being perceived as being responsible for setting limits. A qualitative study with adolescents in Belgium 
found that both boys and girls perceive boys to be the ones who typically ask for sexually suggestive pictures, while girls are perceived to be the ones who may feel pressured into engaging in sexting (Van Ouytsel et al., 2017). These results are in line with the results from a qualitative study conducted with young people in the United Kingdom (Ringrose et al., 2013), which found that boys are largely driven by competitiveness, whereby receiving a sexually explicit picture serves as a proof of a boy's ability of successful negotiation with girls. Girls were regarded as the ones responsible for protecting their reputation and for refusing boys' requests for a picture. Simultaneously, some girls took receiving such a request as a compliment because it confirmed their sexual desirability and physical attractiveness. Both of the abovementioned qualitative studies found that both boys and girls tend to negatively judge girls who engage in sexting via so-called "slut-shaming," while no such judgment was laid on boys. Overall, these studies indicate that sexting scripts are informed by traditional scripts for masculine and feminine sexual behavior. Sexting can therefore be considered a gendered activity, not as much in terms of its prevalence rates but unmistakably in terms of the meanings that are attached to it. To our knowledge, there are no studies that investigate young people's gender-specific norms toward sexting in a quantitative manner.

\section{General and personal scripts}

Individuals differ in the extent to which they integrate culturally dominant scripts in their personal interactions, desires, and behaviors. A qualitative study with adolescent males aged 14-16 years found that they did not personally endorse many hegemonic masculine beliefs about appropriate sexual behavior, such as the idea that the male should be the initiator and that relationships should be focused around sex. Instead, the participants showed a primary interest in intimacy and closeness (Bell et al., 2015). In another qualitative study, conducted with young men and women, all of the respondents tended to acknowledge the existence of hegemonic gendered scripts for sexual behavior. At the same time, the respondents varied in the extent to which they enacted such scripts in their own personal relationships (Masters et al., 2013). Research in the field of sexting also suggests a discrepancy between general perceptions, on one hand, and personal experiences, on the other hand. A North American quantitative study found that $51 \%$ of the girls thought that other girls engage in sexting due to pressure from a boy. In the same study, however, only $12 \%$ of the girls who sent a sext reported that they did so due to pressure (Lee and Crofts, 2015). The idea that girls are pressured into sexting may thus be part of the cultural script surrounding the behavior, whereas pressure likely plays a lesser role in reality.

Krahé et al. (2007a) captured the discrepancy between culturally shared beliefs and personal intentions and experiences as follows: "Knowing a socially shared script does not automatically mean endorsing and enacting it as part of one's own behavioral repertoire" (p. 317). Therefore, it is warranted that studies on sexual scripts make a clear distinction between what people believe to be normative in general and what people believe to be appropriate in their personal situation. In their study on adolescents' sexual scripts, Krahé et al. (2007a) differentiate between the "general script," referring to adolescents' perceptions of how their peers conduct their sexual relationships in general, and the "personal 
script," referring to adolescents' conceptions about their own sexual interactions. The authors found that the personal script was perceived more positively than the general script, in terms of more positively evaluated sexual interactions, a more positive future outlook on the continuation of the relationship after the sexual contact and less inclusion of sexually risky elements. In another study, the authors found that the incorporation of risk elements into the general script was correlated with the incorporation of risk elements into the personal script (Krahé et al., 2007b). This indicates that young people who perceive that sexually risky behavior is likely to occur in general also perceive it as being more likely to occur in their own situation. Thus, the personal script - a person's expectations toward sexual behavior in a given context - is informed by but does not entirely overlap with what is perceived as being the socially prescribed norms for sexual behavior in that context. In the current study, we distinguish between young people's perceived likelihood of sexting among same-aged peers (the general script) versus young people's perceived likelihood of sexting in their personal situation (the personal script).

\section{Factors associated with sexting scripts}

Apart from investigating adolescents' sexting scripts, this study includes factors that are associated with these scripts. The media, with abundant portrayals of male and female sexuality, is commonly researched as a source of information about sexual scripts or ideas about "appropriate sexual behavior." For example, a study among young men showed that increased media exposure was linked to sexual cognitions, which in turn influenced actual sexual behavior (Ward et al., 2011). In terms of media use, concerns have especially been raised regarding the influence of online pornography, which is framed "as a potential source of sex education, and in that context as a bad sex educator" (Spišák and Paasonen, 2016: 8). Accumulating empirical evidence links watching sexually explicit online media content with increasingly permissive and recreational sexual attitudes among teens but also with less progressive gender role attitudes (Brown and L'Engle, 2009; Doornwaard et al., 2015; Lo and Wei, 2005; Peter and Valkenburg, 2006). Concerning the impact on adolescents' sexual behavior, a review of the literature shows that more frequent exposure to porn is consistently related with increased engagement in sexual activity, such as an earlier age of first sexual intercourse and experience with a higher variety of sexual behaviors, as well as with sexual harassment perpetration (Owens et al., 2012). The use of online pornography has also been linked with sexting behavior (Van Ouytsel et al., 2014), especially in the context of high alcohol consumption (Morelli et al., 2017). Overall, these studies suggest that watching online pornography may influence adolescents' perceptions about sexting, whereby increased pornography use may increase the perception that sending sexually explicit pictures to one's romantic partner is the common thing to do.

Another important factor that may shape adolescents' sexting scripts is the sexual behavior they engage in within the offline world. As outlined in the introduction, sexting is now increasingly understood as a technology-mediated expression of normal sexual behavior, which is supported by research evidence that links online and offline sexual behavior. For example, young people with sexual experience are more likely to send and receive sexts than those with no such experience (Rice et al., 2014). Longitudinal 
research has also established that sexting can be a predictor for becoming sexually active later on (Ševčíková et al., 2013; Temple and Choi, 2014). Most studies on sexting and offline sexual behavior are cross-sectional, however, and sexting has been linked to a range of specific offline sexual behaviors, including oral and anal sex, having multiple sex partners at the same time, having a higher number of sex partners, consuming drugs or alcohol prior to also having sex, and having unprotected sex (Klettke et al., 2014; Temple et al., 2012; Ybarra and Mitchell, 2014). It is important to point out, however, that a review of the literature found a consistent link between sexting and general sexual activity offline, while the link between sexting and sexual risk behavior is relatively weak across studies (Kosenko et al., 2017). Based on the studies cited above, it can be expected that having sexual experiences or the anticipation of having such experiences increases the perceived likelihood that sexting will occur.

\section{Current study}

The research literature suggests that sexting has become part of (some) adolescents' sexual repertoire when they become sexually active or romantically involved. There is only very limited empirical knowledge, however, on the sexual scripts - norms toward the behavior - that adolescents hold. Qualitative studies indicate that sexting scripts are gendered, meaning that the behavior that is expected for boys differs from what is expected for girls (Davidson, 2014; Ringrose et al., 2013). In the current study, adolescents' sexting scripts are studied quantitatively by looking at the perceived likelihood that sexting will occur in the context of a relationship. Applying a quantitative methodology offers opportunities for understanding the extent to which sexting is perceived as being normative behavior in this context as well as the extent to which sexting scripts are gender-specific. A distinction is made between asking for and sending sexual images. It is hypothesized that adolescents will perceive boys to be more likely to ask for a picture than girls. A distinction is also made between what adolescents perceive to be likely among same-aged peers (the general script) versus what they perceive to be likely in their own personal situation (the personal script). Thereby, we expected that sexting would be perceived as more likely among peers than in one's personal situation but that there is also a positive relationship between the perceived likelihood of sexting in both scripts. Finally, the study looks at the importance of hypothesized correlates of personal sexting scripts. In addition to the role of the general sexting scripts, we expected that watching online pornography and having more sexual experiences in the offline world, or anticipating such experiences, was related to an increased incorporation of sexting in the personal script.

\section{Method}

\section{Participants and procedure}

The data were gathered in the context of a study on adolescents' online behavior ("Youth Online!'), whereby families were recruited in Flanders, the northern, Dutch-speaking region of Belgium (Symons et al., 2017). In each family, an adolescent aged 13-18years, a mother (figure), and a father (figure) completed a self-administered paper-and-pencil questionnaire. 
Families were recruited between December 2015 and February 2016, with assistance from undergraduate students from the higher education institution where we are based. Families were recruited via the students' personal network, social media, and calls in institutions such as schools. The questionnaires were anonymous, and a stamped envelope was provided for the participants to return the questionnaires via mail after completion. The current study only applies the data that were gathered from adolescents $\left(N=357,45 \%\right.$ male, $M_{\text {age }}=15.40$, standard deviation $[S D]=1.36)$. The research, including the data collection procedure, was granted ethical approval by the Ethics Committee of Antwerp University.

\section{Measures}

General sexting script. To measure how sexting is incorporated into the general script for relationship interactions, the respondents were asked to think of how their same-aged peers would behave in the context of a relationship. The wording of the questions was heteronormative, whereby the respondents were asked to indicate how they perceive boys to behave with a female partner and vice versa. The arguments for applying this method as well as the implications are discussed in the sub-section "limitations" of this article. The question was formulated as follows: "Assume a boy and a girl are in a relationship. How likely is it that ..." - which was followed by specific interactions - "the boy will ask the girl to send a sexually explicit picture" and "the boy will send a sexually explicit picture of himself to his girlfriend." The same interactions were presented with reference to a girl asking and sending a sexually explicit picture to her boyfriend. Each item was answered on a 6-point scale from "very unlikely" (score 1) to "very likely" (score 6).

Personal sexting script. To measure how sexting was incorporated into their personal script, the respondents were asked to think about their own situation. Respondents who were in a relationship were asked to think about their behavior in their current relationship. Respondents who were not in a relationship were instructed to imagine how they would behave if they were in a relationship. No distinction was made between respondents who were versus were not in a romantic relationship at the moment of the survey. This is in line with a former study on sexual scripts among adolescents, in which the participants were asked to indicate how likely they would be to engage in certain sexual behaviors, regardless of the respondent's relationship or sexual experience (Krahé et al., 2007a). The question was formulated as follows - "In your current relationship, or imagine that you would have a relationship, how likely is it that ..."-which was followed by specific interactions: "your partner would ask you to send a sexually explicit picture of yourself" and "your partner would send you sexually explicit pictures of himself or herself." The same situations were described with reference to the respondents asking and sending a sexually explicit picture to their partner. Note that a gender-neutral word ("partner") was used to refer to one's boyfriend or girlfriend, which implies that this question could be completed regardless of the respondent's sexual orientation. Each item was answered on a 6-point scale ranging from "very unlikely" (score 1) to "very likely" (score 6).

Sexual experience and probability/wanting to become sexually active. The respondents were asked whether they had ever had sex with somebody else, with the answering categories 
"yes" and "no." It was clarified that having sex refers to all sorts of sexual behaviors involving genital contact and that only sexual contact on a voluntary basis should be included. Respondents with no experience with sexual contact were asked to indicate how high the chance was that they would have sex in the upcoming year. This was answered on a 5-point Likert-type scale ranging from "very low" (score 1) to "very high" (score 5). The respondents were also asked to indicate the extent to which they wanted to have sex for their first-time in the upcoming year, going from "I would not like that at all" (score 1) to "I would like that very much" (score 5).

Porn use. The respondents were asked how often they watched online porn, which was defined as videos in which people are having sex. This was answered on a 5-point scale ranging from "never" (score 1) to "very often" (score 5).

\section{Data analyses}

Seven respondents who did not fully complete the questions regarding sexting scripts were omitted from the analyses. First, the univariate results of the hypothesized correlates are presented, including the appropriate test statistics for testing gender differences. Second, the results on the general and personal sexting scripts are presented, with attention to gender differences and discrepancies between the general and personal scripts. Cohen's d was used to measure the effect sizes for between-group differences (Cohen, 1988). Third, we measured the extent to which the personal script was related to the general script and the hypothesized correlates.

Two new variables were constructed that indicate the extent to which sexting is incorporated into the general and the personal script, respectively. The variable "sexting in the general script" refers to the accumulated mean score on the four items referring to the general script (how likely it was that the boy would ask for a picture, the girl would ask for a picture, the boy would send a picture and the girl would send a picture). Likewise, the variable "sexting in the personal script" refers to the accumulated mean score on the four items referring to the personal script.

Bivariate partial correlations among both newly constructed variables and the hypothesized correlates are presented, controlling for correlations with age. Stepwise linear regression analyses were performed with the variable sexting in the personal script as a dependent variable, age as a control variable (step one), sexting in the general script as an independent variable (step two), and the hypothesized correlates as independent variables (step three).

In the fourth step, interaction terms were added for the general script with each of the hypothesized correlates to test whether the relationship between the general and personal sexting script was moderated by these correlates.

\section{Results}

\section{Univariate results for the hypothesized correlates of sexting scripts}

About one-fifth of the respondents $(N=69,20 \%)$ had experience with sexual intercourse. A chi-square test did not indicate a statistically significant difference between boys 
$(18 \%)$ and girls $\left(22 \%, \chi^{2}(1)=0.671, p=.413\right)$. Among those who had not yet had sexual intercourse, boys answered more positively than girls to the question about how much they wanted to gain sexual experience in the upcoming year $(M=2.43, S D=1.24$ for boys, and $M=1.95, S D=1.02$ for girls, $t(224)=3.430, p<.001)$. There was no difference between boys and girls in the extent that they believed they would actually have sexual contact in the upcoming year $(M=1.83, S D=1.05$ for boys, and $M=1.62, S D=0.91$ for girls, $t(266)=1.731, p=.085)$. Both genders reported low online porn-watching, but on average, boys indicated that they watched online porn more often $(M=1.89, S D=1.09)$ than $\operatorname{girls} \operatorname{did}(M=1.27, S D=0.58, t(217)=6.360, p<.001)$.

\section{Sexting scripts in the context of a romantic relationship}

Table 1 shows the results for the male and female respondents' perceived likelihood that their peers would engage in sexting in a relationship (the general script). Girls perceived it as being more likely than boys that the boy would ask for a sexually suggestive picture, that the boy would send a picture and that the girl would send a picture. Thus, overall, the girls were more likely than boys to believe that their peers would engage in sexting. Both boys and girls gave the highest score to the item "the boy will ask the girl to send a picture," making this the most normative sexting behavior. A one-sample $t$-test showed that the boys gave a significantly higher score to the likelihood that boys would ask for a picture as compared to a girl, $t(154)=5.077, p<.001$. Also, the girls perceived this behavior to be significantly more likely for boys than for girls, $t(193)=9.168, p<.001$. With regard to sending a picture, male and female respondents perceived it equally likely that a boy or a girl would engage in this behavior $(t(154)=-1.950, p=.053$ for male respondents; $t(192)=0.790, p=.430$ for female respondents). Thus, gender-specific social norms on sexting were found for asking but not for sending sexually suggestive pictures.

With regard to the personal sexting script, Table 1 shows that boys were more likely than girls to expect that they themselves would ask for as well as send a picture. There was no difference between boys and girls with regard to the sexting behavior that they expected from their partner.

To understand the overlap between the general and the personal script, a discrepancy score was calculated for each behavior by subtracting the score on the personal script from the score on the general script, thereby matching the gender of the actors in both scripts. Thus, for boys, the discrepancy score for "sending a sexually suggestive picture" was calculated by subtracting the score on the personal script item "you would send a picture to your girlfriend" from the score on the general script item "the boy will send a picture to his girlfriend." The average discrepancy scores are included in Table 1. All scores were positive; thus, the respondents perceived the different sexting behaviors as being more likely for their peers than for themselves. Independent samples $t$-tests showed that the discrepancy scores were significantly larger for girls than for boys on all items except for asking for a picture. Girls incorporated more sexting into the general script than boys but incorporated less sexting into their personal script. For boys, the biggest discrepancy score was found for asking for a sexually suggestive picture $(M=1.19)$; thus, they found it much more likely that same-aged boys would ask for a picture as 
Table I. Expectations toward sexting in the general and personal script according to gender.

\begin{tabular}{|c|c|c|c|c|}
\hline & $\begin{array}{l}\text { Boys } \\
(N=155) \\
M(S D)\end{array}$ & $\begin{array}{l}\text { Girls } \\
(N=194) \\
M(S D)\end{array}$ & $t$-value & Cohen's d \\
\hline \multicolumn{5}{|l|}{$\begin{array}{l}\text { General script (perceived likelihood) } \\
\text { (I = "very unlikely" to 6 = "very likely") }\end{array}$} \\
\hline The boy will ask to send a picture & $3.06(1.46)$ & $3.44(\mathrm{I} .4 \mathrm{I})$ & $-2.42^{*}$ & -0.26 \\
\hline The boy will send a picture & $2.57(1.31)$ & $3.17(1.42)$ & $-4.02 * * *$ & -0.44 \\
\hline The girl will ask to send a picture & $2.47(1.31)$ & $2.51(1.15)$ & -0.29 & -0.03 \\
\hline The girl will send a picture & $2.77(1.44)$ & $3.09(1.40)$ & $-2.13^{*}$ & -0.23 \\
\hline \multicolumn{5}{|l|}{$\begin{array}{l}\text { Personal script (perceived likelihood) } \\
\text { (I = "very unlikely" to } 6=\text { "very likely") }\end{array}$} \\
\hline You would ask your partner a picture & $1.87(1.23)$ & $\mathrm{I} .47(0.95)$ & $3.36 * *$ & 0.37 \\
\hline You would send your partner a picture & $1.72(1.14)$ & $1.45(0.90)$ & $2.37^{*}$ & 0.26 \\
\hline Your partner would ask you a picture & $1.86(1.10)$ & $2.03(1.25)$ & -1.31 & -0.15 \\
\hline Your partner would send you a picture & $2.05(1.29)$ & $1.96(1.21)$ & 0.61 & 0.07 \\
\hline \multicolumn{5}{|c|}{ Discrepancy scores (score on general script minus score on personal script) } \\
\hline Asking a picture from partner & $1.19(1.26)$ & $1.04(1.21)$ & 1.14 & 0.12 \\
\hline Sending a picture to partner & $0.86(1.19)$ & $1.63(1.40)$ & $-5.57 * * *$ & -0.60 \\
\hline Partner will ask a picture & $0.61(1.07)$ & $\mathrm{I} .4 \mathrm{I}(\mathrm{I} .33)$ & $-6.19 * * *$ & -0.66 \\
\hline Partner will send a picture & $0.72(1.16)$ & $1.20(1.31)$ & $-3.62 * * *$ & -0.39 \\
\hline
\end{tabular}

$* p<.05 ; * *<.01$; and $* * * p<.001$.

compared to what they would do themselves. For girls, the biggest discrepancy score was found for sending a sexually suggestive picture $(M=1.63)$, suggesting that the girls found it much more likely that same-aged girls would send a picture as compared to what they would do themselves.

\section{Factors that inform the personal sexting script}

As discussed in the section "Method," two new variables were constructed that indicate the extent to which sexting was incorporated into the general and the personal script. Therefore, the mean score was calculated for the four items referring to asking for and sending sexually suggestive pictures in both respective scripts, with a higher score implicating that sexting is believed to be more likely to occur. For the general script, scores ranged from 1 to $6(M=2.76, S D=1.21)$. For the personal script, scores ranged from 1 to $4.75(M=1.62, S D=0.85)$. Both scripts were positively correlated with the respondent's age, with $r(269)=.35, p<.001$ for the personal script and $r(270)=.27, p<.001$ for the general script. Table 2 shows the partial correlations for all of the study variables according to gender, while controlling for the respondent's age. For both genders, there was a strong correlation between sexting in the general and the personal script. Having had sexual experience, either wanting or expecting such experience in the near future and watching online porn were positively correlated with sexting in the general and personal scripts. 
Table 2. Partial correlations controlling for respondent's age, according to gender.

\begin{tabular}{|c|c|c|c|c|}
\hline & \multicolumn{2}{|c|}{ Male respondents } & \multicolumn{2}{|c|}{ Female respondents } \\
\hline & $\begin{array}{l}\text { General } \\
\text { script }\end{array}$ & $\begin{array}{l}\text { Personal } \\
\text { script }\end{array}$ & $\begin{array}{l}\text { General } \\
\text { script }\end{array}$ & $\begin{array}{l}\text { Personal } \\
\text { script }\end{array}$ \\
\hline Sexting in general script & - & $.582 * * *$ & - & $.483 * * *$ \\
\hline Sexting in personal script & $.582^{* * *}$ & - & $.483 * * *$ & - \\
\hline Sexual experience (no/yes) & $.221^{* *}$ & $.339 * * *$ & .020 & $.147^{*}$ \\
\hline Probability becoming sexually active & .112 & $.202^{*}$ & $.176 *$ & $.307 * * *$ \\
\hline Wanting to become sexually active & $.209 *$ & $.316 * * *$ & $.247^{* *}$ & $.426 * * *$ \\
\hline Watching online porn & $.413^{* * *}$ & $.495 * * *$ & $.201 * *$ & $.397 * * *$ \\
\hline
\end{tabular}

Missing values were omitted pairwise.

$* p<.05 ; * *<.01$; and $* * * p<.001$.

Stepwise linear regression analyses were applied to investigate the relationship between sexting in the personal script and in the general script and the hypothesized correlates. Table 3 shows the results for all respondents, while Table 4 shows the results for only those respondents who had no former experience with sexual contact. Table 3 shows that for both genders, the personal sexting script score was predicted by the general sexting script score. Adding the variables sexual experience and watching online porn only slightly decreased the predictive value of the general sexting script. Having sexual experience was not a strong predictor for the personal sexting script $(p<.05)$, and this variable had no significance for girls. Watching online porn was positively related to the personal sexting script and to the same extent for both boys and girls. The predictive value of age disappeared when including additional variables to the model (model 3). Thus, older adolescents found it more likely that sexting would occur in their personal relationship because they also perceived it as being more common among same-aged peers and because they were more sexually experienced. For boys only, model 4 shows a positive interaction effect between the general script and watching online porn, which suggests that both factors reinforce each other in relation to the personal script. For girls, no such interaction effect occurred. Large proportions of the total variability in the personal sexting script were explained by the selected variables ( $62 \%$ for boys and $41 \%$ for girls).

Table 4 shows that among respondents who did not have experience with sexual contact, the personal sexting script score was also predicted by the general sexting script score when controlling for the effect of the respondent's age. The prospect of becoming sexually active or wanting to become sexually active in the near future was not related to the personal sexting script for boys. For girls, wanting to become sexually active was related to a higher personal sexting script score. For boys as well as girls, watching online porn was related to the personal sexting script score when controlling for the effect of age and the general sexting script. Model 4 of the regression analyses indicates an interaction effect for the general script and the respondent's perceived probability that he or she would become sexually active in the upcoming year. For both boys and girls, the relationship between the general and personal scripts was stronger when they believed that they would become sexually active in the upcoming year. The model explained large 
Table 3. Stepwise linear regression analysis with sexting in the personal script as the outcome variable (standardized beta-values are presented)_All respondents.

\begin{tabular}{|c|c|c|}
\hline & $\begin{array}{l}\text { Male respondents } \\
(N=143)\end{array}$ & $\begin{array}{l}\text { Female respondents } \\
(N=189)\end{array}$ \\
\hline \multicolumn{3}{|l|}{ Model I } \\
\hline Age & $.525 * * *$ & $.262 * * *$ \\
\hline$R^{2}$ (F change) & $.276(54.010 * * *)$ & $.069\left(13.833^{* * *}\right)$ \\
\hline \multicolumn{3}{|l|}{ Model 2} \\
\hline Age & $.26 \mathrm{I} * * *$ & .066 \\
\hline General script & $.56 \mathrm{I} * * *$ & $.525 * * *$ \\
\hline$R^{2}$ ( $F$ change) & $.521\left(72.033^{* * *}\right)$ & $.306(64.106 * * *)$ \\
\hline \multicolumn{3}{|l|}{ Model 3} \\
\hline Age & .123 & .024 \\
\hline General script & $.408 * * *$ & $.46 I * * *$ \\
\hline Sexual experience $(r e f=n o)$ & $.165^{*}$ & .103 \\
\hline Watching online porn & $.278^{* * *}$ & $.267 * * *$ \\
\hline$R^{2}$ (F change) & $.598(13.403 * * *)$ & $.390\left(12.74 I^{* * *}\right)$ \\
\hline \multicolumn{3}{|l|}{ Model 4} \\
\hline Age & $.153^{*}$ & .023 \\
\hline General script & .126 & .246 \\
\hline Sexual experience $(r e f=n o)$ & $.477^{*}$ & -.250 \\
\hline Watching online porn & -.238 & .003 \\
\hline General script vs sexual experience & -.397 & .374 \\
\hline General script vs watching porn & $.785^{* *}$ & .349 \\
\hline$R^{2}$ (F change $)$ & $.623(4.63 \mid *)$ & $.4 I I\left(3.256^{*}\right)$ \\
\hline
\end{tabular}

$*_{p}<.05 ; * * p .01 ;$ and $* * * p<.001$.

proportions of the total variability of the personal sexting script scores ( $63 \%$ for boys and $45 \%$ for girls).

\section{Discussion}

Scripting theory suggests that cognitive representations of what sexual behavior in a given context looks like will shape that behavior when the context is actually presented. To better understand how sexting becomes part of the sexual repertoire when young people enter a relationship, this study investigated "sexting scripts" held by young people aged 13-18years. We investigated the extent to which sexting was perceived to be a "likely behavior to occur" when in a relationship, the extent to which sexting scripts are gender-specific, and which factors are related to sexting scripts.

\section{(Gender-specific) sexting scripts}

Young people's expectations about sexting in the context of a romantic relationship were highly diverse; therefore, it cannot be concluded that sexting scripts are culturally shared. 
Table 4. Stepwise linear regression analysis with sexting in the personal script as the outcome variable (standardized beta-values are presented) — respondents with no experience in sexual contact.

\begin{tabular}{lll}
\hline & $\begin{array}{l}\text { Male respondents } \\
(N=115)\end{array}$ & $\begin{array}{l}\text { Female respondents } \\
(N=147)\end{array}$ \\
\hline Model I & & \\
Age & $.383^{* * *}$ & $.180^{*}$ \\
$R^{2}(F$ change) & $.147\left(19.570^{* * *}\right)$ & $.033\left(4.912^{*}\right)$ \\
Model 2 & & \\
Age & $.161^{*}$ & -.009 \\
General script & $.603^{* * *}$ & $.553^{* * *}$ \\
$R^{2}(F$ change) & $.461\left(65.963^{* * *}\right)$ & $.303\left(56.250^{* * *}\right)$ \\
Model 3 & & \\
Age & .055 & -.086 \\
General script & $.480^{* * *}$ & $.440^{* * *}$ \\
Probability to become sexually active & .012 & -.067 \\
Wanting to become sexually active & .182 & $.35 I^{* *}$ \\
Watching online porn & $.199 *$ & $.172^{*}$ \\
$R^{2}(F$ change) & $.544\left(6.692^{* * *}\right)$ & $.424\left(9.915^{* * *}\right)$ \\
Model 4 & & \\
Age & .099 & -.050 \\
General script & -.170 & .135 \\
Probability to become sexually active & -.375 & -.243 \\
Wanting to become sexually active & -.089 & .206 \\
Watching online porn & -.072 & .115 \\
General script vs probability sexually active & $.876^{*}$ & $.893^{*}$ \\
General script vs wanting sexually active & .145 & -.419 \\
General script vs watching porn & .312 & .091 \\
$R^{2}(F$ change) & $.627\left(7.885^{* * * *}\right)$ & $.452(2.417)$ \\
\hline
\end{tabular}

$*_{p}<.05 ; *_{p}<.01$; and $*_{*} * p<.001$.

At the same time, expectations toward sexting were found to be gendered, in terms of both what the respondents perceived to be likely among same-aged peers (the general script) and what they perceived to be likely in their own personal situation (the personal script). The most normative sexting behavior was a boy asking for a sexually suggestive picture from his girlfriend, as this behavior received the highest score on perceived likelihood by both the male and female respondents. Also in the personal sexting script, boys found it more likely than girls that they themselves would ask for as well as send a sexually suggestive picture. These results are in line with our expectations based on prevailing traditional sexual scripts that prescribe sexual predatory behavior for boys against sexual boundary-setting for girls (Tolman et al., 2015). This result also substantiates what Salter et al. (2013) argued, namely that sexting is subject to the same gendered social relations that define offline relations among young people and that it should be considered as "part of a broader pattern of gendered sexual negotiations" (p. 304). Yet, 
while asking for a picture was perceived as being more likely for a boy than for a girl, boys found it rather unlikely that they would actually engage in such behavior themselves. This is in line with former research indicating that young people incorporate more sexual risk-taking into the general and their personal sexual scripts (Krahé et al., 2007a). Thus, while young people may perceive certain sexting norms, they do not necessarily apply those norms to themselves.

When interpreting these results, it is important to point out that sexual double standards around sexting are not harmless and have real-life consequences. Indeed, sexual double standards are the basis for more severe reputational loss for girls as compared to boys whose engagement in sexting becomes exposed (Ringrose et al., 2013). Just as offline sexual aggression can be related to sexist attitudes (Lancasse and Mendelson, 2007), there are indications that harmful sexting (or what was labeled as "aggravated sexting") is also linked to sexist attitudes (Morelli et al., 2016). Furthermore, it is important to point out that girls may perceive themselves as being less likely than boys to send a sexually suggestive picture but that in reality, girls are not less likely than boys to engage in sexting (Cooper et al., 2016). This suggests a tension between girls' expectations toward themselves, on one hand, and their actual behavior, on the other hand. It is possible that girls are more motivated to uphold a self-image in which they would not engage in sexting due to the negative judgments laid on girls who do (Ringrose et al., 2013). As pointed out in former studies, the moral panic around sexting focuses on girls, who are depicted as being at risk of sexual commodification and abuse and who are held responsible to a greater extent than boys are when sexting goes wrong (Salter et al., 2013). Qualitative research shows that both boys and girls perceive the potential consequences of sexting as being more severe for girls than for boys, such as in terms of slutshaming, social condemnation, and reputational loss (Davidson, 2014). Thus, the gendered double standard surrounding sexting implies that girls need to juggle between the demands from behavioral norms, on one hand, and experiencing their sexuality and negotiating boys' requests, on the other hand.

\section{Factors that influence sexting scripts}

The second aim of this study was to investigate the relationship between adolescents' personal sexting scripts and a series of hypothesized correlates. Young people who found it more likely that same-aged peers would engage in sexting also found it more likely that they themselves would engage in sexting. This is in line with former studies indicating that peers influence online sexual self-presentations (Baumgartner et al., 2015). In addition to being informed by the general script, the personal sexting script was related to online and offline sexual experiences. Having experience with sexual contact, for boys, and wanting to gain such experience, for girls, increased the incorporation of sexting into their personal script. Interestingly, for both boys and girls with no former sexual experience, having the expectation of becoming sexually active in the near future reinforced the relationship between the general and the personal script. The results are in line with studies that link online and offline sexual behaviors (Gordon-Messer et al., 2013; Temple and Choi, 2014), suggesting that sexting is best understood from the broader range of sexual behavior of young people and that it is part of their sexual development. The 
current study adds to this literature by showing that young people's cognitive expectations toward sexting are also linked to their broader sexual development.

Porn use had a positive effect on the incorporation of sexting into the personal script for both boys and girls, which suggests that young people's ideas about what sexting behavior they would engage in stems from different sources, including what they see in the media. Interestingly, the incongruence between what is socially prescribed as appropriate sexual behavior for girls (sexual restraint) versus the narratives found in porn use (sexual responsiveness) does not limit girls from using these media messages to shape their personal scripts to the same extent as boys do. Indeed, under the prevailing sexual double standards, sexual behavior is more socially rewarded for boys than for girls (Tolman et al., 2015), which might encourage boys more than girls to incorporate what they see in the media into their personal behavioral scripts. A difference that did occur between boys and girls, however, was that for boys, watching porn and the perceived peer norms regarding sexting both reinforced each other in relation to the personal sexting script, while this was not the case for girls. From this, it appears that watching porn makes adolescent boys more susceptible to peer influence, although no statements on causality can be made due to the cross-sectional design of this study. It is unclear why this interaction effect between porn use and the influence of the general sexting script did not occur for girls. One explanation would be that boys indicated that they watched porn more often than girls did, and an interaction effect with the perceived peer norms may require a certain amount of porn-watching.

The results on porn use are not surprising, considering that porn use has been linked to sexual attitudes and behavior, including with sexting behavior (Van Ouytsel et al., 2014). How the relationship between porn use and sexting scripts should be valued is not straightforward and depends on multiple factors. While porn use largely remains framed as a risk factor for adverse outcomes, calls have been made for a more nuanced view. As such, the effects of porn use depend on the extent to which the pornographic content is perceived to be realistic (Baams et al., 2015; Peter and Valkenburg, 2006), and porn use can also play a positive role in youths' sexual socialization, such as in terms of satisfying sexual curiosity or negotiating normative expectations concerning sexuality and gender (Spišák and Paasonen, 2016). Hence, relevant questions to ask are, "What are the messages that young people take away from the porn they watch?" and "In what ways does watching porn increase the perceived likelihood of sexting?" Clearly, the link between porn use and sexting is problematic if watching porn increases the perception that it is acceptable to pressure somebody into sending sexually suggestive pictures, or if it puts pressure on young people to present themselves in an objectified, sexual manner. If watching porn lowers young people's boundaries for sexual self-exploration and sexual expression, then the link with sexting may not necessarily be negative. To better understand such relations, it is necessary to understand sexting from a more complete and nuanced perspective that takes into account the motivations and contexts in which it takes place. So far, there are no indications as to how the relationship between porn use and sexting manifests itself in young people. Qualitative research has found that boys themselves believe that media messages (but not porn use specifically) influence their sexting behavior because such messages leave the impression that it is normal to pursue sexts (Davidson, 2014). 


\section{Limitations}

First, the study did not distinguish between respondents according to their sexual orientation. The data were gathered as part of a larger study on Internet use among adolescents and parent-child interactions in the context of Internet use. Considering the topic of the research, it was deemed too sensitive and inappropriate to include questions on sexual orientation, and only a limited number of questions on previous sexual experiences were added. The wording of the questions referring to the sexting scripts was such that any respondent could complete these questions regardless of his or her sexual orientation. The items for measuring the general sexting script referred to the perceived behavior among other boys and girls. We suggest that any respondent could have completed these items, regardless of sexual orientation. The items for measuring the personal sexting script referred to what the respondent perceived to be likely for him or her and what the respondent believed his or her partner would do. The Dutch word that was used to refer to one's boyfriend or girlfriend (lief) is gender neutral; thus, the items could be completed regardless of sexual orientation. It remains unclear, however, how many respondents filled in these items with a same-sex partner in mind. We acknowledge that the exclusion of sexual orientation in this study was problematic and that different results may be achieved when looking at sexting scripts among youth who do not identify as heterosexual. Studies suggest that sexual-minority youth may be particularly motivated to explore their sexuality online due to the stigma and discrimination they experience offline (Kosenko et al., 2017; Ybarra and Mitchell, 2015), which may result in different sexting scripts. It is worth pointing out that the inclusion of sexual orientation in this study would pose serious practical problems, as sexual orientation is not an easily applicable concept. Sexual orientation is best considered as a continuum (Epstein et al., 2012), and asking the respondent to indicate the sexual orientation with which he or she most identifies would still not give certainty over the gender of the person whom the respondent held in mind when completing the questions.

Second, no differentiation was made between respondents who were and who were not involved in a romantic relationship. It is possible that the respondents completed the questions differently according to whether they were thinking about an actual partner versus a fictional partner. Indeed, being in a relationship, or having relationship experience, could alter one's expectations toward sexting; hence, this factor should be considered in future studies. Here, we refer to the study by Krahé et al. (2007a) in which adolescents' scripts on the first-time they would have sex with a new partner were studied, by asking how likely they perceived certain behaviors to occur in that context. Also in that study, no distinction was made between respondents who did have a firsttime sexual experience and those who did not, although being more sexually experienced did affect the respondents' sexual script. We also point out that asking about adolescents' relationship status in a quantitative survey is a rather complicated matter. Adolescent relationships can be very fluid and short-lived, and the difference between dating somebody and being in a relationship can be vague (Conolly and McIsaac, 2011). Therefore, adolescents" understandings of "being in a relationship" may be very different from what the researcher intends, and measuring relationship status would require detailed information on what is specifically meant by "being in a relationship." 
Finally, the study did not differentiate between young people who had experience with sexting and those who did not. The age of the respondents ranged 13-18 years, and sexting is a rather uncommon behavior among younger adolescents. In our study, 31 respondents had experiences with sending a sexually suggestive image to someone else, and these respondents were all 15 years old or older (reference removed for anonymity). A study with a longitudinal research design would be particularly useful to understand how adolescents' expectations toward future sexting are shaped by former experiences or, vice versa, how expectations toward sexting predict the future sexting behavior.

\section{Conclusion and implications}

Overall, young people consider sexting in the context of a relationship as being rather unlikely to occur; thus, it cannot be regarded as normative relationship behavior. Sexting scripts are gendered, with different expectations toward boys and girls, and young people's personal sexting scripts are strongly related to what they perceive to be common among peers as well as to their offline sexual experiences and porn use.

The results of this study have implications in terms of prevention messages directed at teens. As pointed out by other researchers, there is a need to move beyond scare tactics and the framing of young people who engage in sexting as naïve and impulsive decisionmakers (e.g. Albury and Crawford, 2012; Henry and Powell, 2015). Instead, young people need to be supported in sexual decision-making, including when it concerns sexting. The results highlight the importance of including sexting in regular sex education programs, in which attention needs to go to discussing peer norms and pornography. Furthermore, the persistent sexual double standard around the behavior needs to be addressed, as this is a vehicle for harmful sexting. By gaining insights into the factors that shape their own behavior and expectations toward sexting, young people can become better decision-makers when it comes to sexting.

Second, the study has implications in terms of future research. It is important to continue efforts toward understanding sexting as part of the broader sexual development of young people. Such understanding implies a better knowledge of how sexting becomes part of their sexual repertoire. While this study focused on sexting in the context of a romantic relationship, future studies can consider sexting scripts in different contexts such as flirtation.

Furthermore, this study only included a limited number of factors that may be related to sexting scripts. Young people receive diverse and possibly opposing socializing messages, including anti-sexting messages from parents versus continuous exposure to highly sexualized media content, for example, music videos, which would function as a motivator to engage in sexting (Davidson, 2014; Van Ouytsel et al., 2014). Future research could focus more on how young people make sense of those diverse messages.

Finally, we suggest that future studies pay more attention to the perceptions toward sexting among sexual-minority youth.

\section{Acknowledgements}

The authors gratefully acknowledge support of the Research Fund of Odisee. The study design, data collection, analysis, interpretation of the data, writing of the report, and the decision to submit 
the article for publication were the sole responsibility of the authors and were in no way influenced by the Research Fund of Odisee.

\section{Funding}

The author(s) received no financial support for the research, authorship, and/or publication of this article.

\section{References}

Albury K and Crawford K (2012) Sexting, consent and young people's ethics: beyond Megan's story. Continuum: Journal of Media \& Cultural Studies 26(3): 463-473.

Angelides S (2013) "Technology, hormones, and stupidity": the affective politics of teenage sexting. Sexualities 16(5/6): 665-689.

Baams L, Overbeek G, Dubas JS, et al. (2015) Perceived realism moderates the relation between sexualized media consumption and permissive sexual attitudes in Dutch adolescents. Archives of Sexual Behavior 44(3): 743-754.

Barrense-Dias Y, Berchtold A, Surís JC, et al. (2017) Sexting and the definition issue. Journal of Adolescent Health 61: 544-554.

Baumgartner SE, Sumter SR, Peter J, et al. (2014) Does country context matter? Investigating the predictors of teen sexting across Europe. Computers in Human Behavior 34: 157-164.

Baumgartner SE, Sumter SR, Peter J, et al. (2015) Sexual self-presentation on social network sites: who does it and how is it perceived? Computers in Human Behavior 50: 91-100.

Bell DL, Rosenberger JG and Ott MA (2015) Masculinity in adolescent males' early romantic and sexual heterosexual relationships. American Journal of Men's Health 9(3): 201-208.

Bianchi D, Morelli M, Baiocco R, et al. (2016) Psychometric properties of the Sexting Motivations Questionnaire for adolescents and young adults. Rassegna Di Psicologia 33(3): 5-18.

Bianchi D, Morelli M, Baiocco R, et al. (2017) Sexting as the mirror on the wall: body-esteem attribution, media models, and objectified-body consciousness. Journal of Adolescence 61: $164-117$.

Bowleg L, Burkholder GJ, Noar SM, et al. (2015) Sexual scripts and sexual risk behaviors among Black heterosexual men: development of the sexual scripts scale. Archives of Sexual Behavior 44(3): 639-654.

Brown JD and L'Engle KL (2009) X-rated: sexual attitudes and behaviors associated with US early adolescents' exposure to sexually explicit media. Communication Research 36: 129-151.

Chalfen R (2009) "It's only a picture": sexting, "smutty" snapshots and felony charges. Visual Studies 24: 258-268.

Cohen J (1988) Statistical Power Analysis for the Behavioral Sciences. Hillsdale, NJ: Lawrence Erlbaum Associates.

Conolly J and McIsaac C (2011) Romantic relationships in adolescence. In: Underwood MK and Rosen LH (eds) Social Development: Relationships in Infancy, Childhood, and Adolescence. London: Guilford Press, pp. 180-203.

Cooper K, Quayle E, Jonsson L, et al. (2016) Adolescents and self-taken sexual images: a review of the literature. Computers in Human Behavior 55(3): 706-716.

Davidson J (2014) Sexting: Gender and Teens. Rotterdam: Sense Publishers.

Doornwaard SM, Bickham DS, Rich M, et al. (2015) Adolescents' use of sexually explicit internet material and their sexual attitudes and behavior: parallel development and directional effects. Developmental Psychology 51(10): 1476-1488.

Döring N (2014) Consensual sexting among adolescents: risk prevention through abstinence education or safer sexting? Cyberpsychology: Journal of Psychosocial Research on Cyberspace 8(1): article 9. 
Epstein R, McKinney P, Fox S, et al. (2012) Support for a fluid-continuum model of sexual orientation: a large-scale internet study. Journal of Homosexuality 59: 1356-1381.

Gagnon W and Simon JH (2005) Sexual Conduct: The Social Sources of Human Sexuality. 2nd edn. London: Aldine Transaction.

Gordon-Messer D, Bauermeister JA, Grodzinski A, et al. (2013) Sexting among young adults. Journal of Adolescent Health 52(3): 301-306.

Hasinoff AA (2016) How to have great sext: consent advice in online sexting tips. Communication and Critical/Cultural Studies 13: 58-74.

Henry N and Powell A (2015) Beyond the "sext": technology-facilitated sexual violence and harassment against adult women. Australian \& New Zealand Journal of Criminology 48(1): 104-118.

Holman A and Sillars A (2012) Talk about "hooking up": the influence of college student social networks on nonrelationship sex. Health Communication 27(2): 205-2016.

Klettke B, Hallford DJ and Mellor DJ (2014) Sexting prevalence and correlates: a systematic literature review. Clinical Psychology Review 34(1): 44-53.

Kosenko K, Luurs G and Binder AR (2017) Sexting and sexual behavior, 2011-2015: a critical review and meta-analysis of a growing literature. Journal of Computer-Mediated Communication 22: 141-160.

Krahé B, Bieneck S and Scheinberger-Olwig R (2007a) Adolescents' sexual scripts: schematic representations of consensual and nonconsensual heterosexual interactions. Journal of Sex Research 44(4): 316-327.

Krahé B, Bieneck S and Scheinberger-Olwig R (2007b) The role of sexual scripts in sexual aggression and victimization. Archives of Sexual Behavior 36(5): 687-701.

Lancasse A and Mendelson MJ (2007) Sexual coercion among adolescents. Journal of Interpersonal Violence 22: 424-437.

Lee $\mathrm{M}$ and Crofts T (2015) Gender, pressure, coercion and pleasure: untangling motivations for sexting between young people. British Journal of Criminology 55(3): 454-473.

Lenhart A (2009) Teens and sexting. How and why minor teens are sending sexually suggestive nude or nearly nude images via text messaging. Washington D.C.: Pew Research Center.

Lim SS (2013) On mobile communication and youth "deviance": beyond moral, media and mobile panics. Mobile Media \& Communication 1: 96-101.

Lo VH and Wei R (2005) Exposure to internet pornography and Taiwanese adolescents' sexual attitudes and behavior. Journal of Broadcasting and Electronic Media 49(2): 221-237.

Masters NT, Casey E, Wells EA, et al. (2013) Sexual scripts among young heterosexually active men and women: continuity and change. Journal of Sex Research 50(5): 409-420.

Mitchell KJ, Finkelhor D, Jones LM, et al. (2012) Prevalence and characteristics of youth sexting: a national study. Pediatrics 129(1): 13-20.

Morelli M, Bianchi D, Baiocco R, et al. (2016) Not-allowed sharing of sexts and dating violence from the perpetrator's perspective: the moderation role of sexism. Computers in Human Behavior 56: 163-169.

Morelli M, Bianchi D, Baiocco R, et al. (2017) Sexting behaviors and cyber pornography addiction among adolescents: the moderating role of alcohol consumption. Sexuality Research and Social Policy 14: 113-121.

Morrison DM, Masters NT, Wells EA, et al. (2015) "He enjoys giving her pleasure": diversity and complexity in young men's sexual scripts. Archives of Sexual Behavior 44(3): 655-688.

Owens EW, Behun RJ, Manning JC, et al. (2012) The impact of internet pornography on adolescents: a review of the research. Sexual Addiction \& Compulsivity: The Journal of Treatment \& Prevention 19: 99-122. 
Peter J and Valkenburg PM (2006) Adolescents' exposure to sexually explicit online material and recreational attitudes toward sex. Journal of Communication 56(4): 639-660.

Rice E, Gibbs J, Winetrobe H, et al. (2014) Sexting and sexual behavior among middle school students. Pediatrics 134(1): e21-e28.

Ringrose J, Harvey L, Gill R, et al. (2013) Teen girls, sexual double standards, and "sexting": gendered value in digital image exchange. Feminist Theory 14(3): 305-323.

Ryan KM (2011) The relationship between rape myths and sexual scripts: the social construction of rape. Sex Roles 65(11/12): 774-782.

Sakaluk JK, Todd LM, Milhausen R, et al. (2014) Dominant heterosexual sexual scripts in emerging adulthood: conceptualization and measurement. Journal of Sex Research 51(5): 516-531.

Salter M, Crofts T and Lee M (2013) Beyond criminalization and responsibilisation: sexting, gender and young people. Current Issues in Criminal Justice 24(3): 301-316.

Ševčíková A, Vazsonyi AT, Širůček J, et al. (2013) Predictors of online and offline sexual activities and behaviors among adolescents. Cyberpsychology, Behavior, and Social Networking 16(8): 618-622.

Spišák S and Paasonen S (2016) Bad education? Childhood recollections of pornography, sexual exploration, learning and agency in Finland. Childhood 24(1): 99-112.

Symons K, Ponnet K, Walrave M, et al. (2017) Jongeren Online! Onderzoeksresultaten [Youth Online! Research Results]. Brussel: Kenniscentrum Hoger Instituut voor Gezinswetenschappen.

Temple JR, Paul JA, van den Berg P, et al. (2012) Teen sexting and its association with sexual behaviors. Archives of Pediatrics \& Adolescent Medicine 166(9): 828-833.

Temple JR and Choi HJ (2014) Longitudinal association between teen sexting and sexual behavior. Pediatrics 134(5): e1287-e1292.

Tolman DL, Davis BR and Bowman CP (2015) "That's just how it is": a gendered analysis of masculinity and femininity ideologies in adolescent girls' and boys' heterosexual relationships. Journal of Adolescent Research 31(1): 3-31.

Van de Bongardt D, Reitz E, Sandfort T, et al. (2014) A meta-analysis of the relations between three types of peer norms and adolescent sexual behavior. Personality and Social Psychology Review 19(3): 203-234.

Van Ouytsel J, Ponnet K and Walrave M (2014) The associations between adolescents' consumption of pornography and music videos and their sexting behavior. Cyberpsychology, Behavior, and Social Networking 17(12): 772-778.

Van Ouytsel J, Van Gool E, Walrave M, et al. (2017) Sexting: adolescents' perceptions of the applications used for, motives for, and consequences of sexting. Journal of Youth Studies 20: 446-470.

Vanden Abeele M, Campbell SW, Eggermont S, et al. (2014) Sexting, mobile porn use, and peer group dynamics: boys' and girls' self-perceived popularity, need for popularity, and perceived peer pressure. Media Psychology 17(1): 6-33.

Walker K and Sleath E (2017) A systematic review of the current knowledge regarding revenge pornography and non-consensual sharing of sexually explicit media. Aggression and Violent Behavior 36: 9-24.

Walrave M, Ponnet K, Van Ouytsel J, et al. (2015) Whether or not to engage in sexting: explaining adolescent sexting behaviour by applying the prototype willingness model. Telematics and Informatics 32(4): 796-808.

Ward LM, Epstein M, Caruthers A, et al. (2011) Men's media use, sexual cognitions, and sexual risk behavior: testing a mediation model. Developmental Psychology 47(2): 592-602.

Willard NE (2010) Sexting and youth: Achieving a rational response. Journal of Social Sciences 6: $542-562$. 
Wiederman MW (2005) The gendered nature of sexual scripts. The Family Journal 13(4): 496-502.

Wolak J and Finkelhor D (2011) Sexting: A Typology. Durham, NH: Crimes against Children Research Center. Available at: http://unh.edu/ccrc/pdf/CV231_Sexting\%20Typology\%20 Bulletin_4-6-11_revised.pdf

Ybarra ML and Mitchell KJ (2014) "Sexting" and its relation to sexual activity and sexual risk behavior in a national sample of adolescents. Journal of Adolescent Health 55(6): 757-764.

Ybarra ML and Mitchell KJ (2015) A national study of lesbian, gay, bisexual (LGB), and nonLGB youth sexual behavior in online and in person. Archives of Sexual Behavior 45(6): 1357-1372.

\section{Author biographies}

Katrien Symons (Ph.D) is a researcher at the Higher Institute for Family Studies, Odisee. Her major research interests include positive youth development, online and offline problem behavior, sex work, and sexual health and behavior among young people.

Koen Ponnet (Ph.D), is social psychologist who conducts research in the field of (media)psychology, sociology and communication studies. He is an assistant professor and researcher at the University of Antwerp and Ghent University. His main research interests are the (mental) health, risk and problem behaviors of adolescents and adults, both off-line and on-line.

Michel Walrave (Ph.D) is a professor at the Department of Communication Studies of the University of Antwerp. His research is centered around online self-disclosure and privacy. He investigates individuals' self-disclosure and privacy in interpersonal online communication on social network sites. More particularly, his research focuses on self-disclosure's opportunities (e.g., social capital) as well as risks (e.g., cyberbullying). He also investigates sensitive disclosures (e.g., sexting). Next to interpersonal self-disclosures, he also studies internet users' entrusting of personal data to businesses and how consumers deal with new forms of interactive marketing.

Wannes Heirman (Ph.D) is a postdoctoral researcher and lecturer affiliated with the University of Antwerp and the Artesis Plantijn College in Antwerp. His research interest encompasses several strands (e.g., adolescents' involvement in online privacy-related risks and cyberbullying). He has published extensively in international peer-reviewed journals on these topics. For an overview of these publications, please visit his personal webpage on the following address: https://www.uantwerpen.be/nl/personeel/wannes-heirman/publicaties/ 